\title{
Impact of Mass Media upon Juvenile Delinquency in Basra Central Prison and AL- Maqal Police Station
}

\author{
Haider Falih Jabbar ${ }^{1}$, Ali Kareem Al-Juboori ${ }^{2}$ \\ ${ }^{1}$ M.Sc., Academic Nursing Specialist, High Institute of Health Vocational, Ministry of Health. PHD Student. \\ ${ }^{2}$ Ph.D. Prof., Department of Psychiatric and Mental Health Nursing, College of Nursing, University of Kerbala
}

\begin{abstract}
Aim: This study aimed to determine the impact of mass media upon juvenile delinquency in Basra Central Prison and AL- Maqal Police Station

Subjects and Methods: A descriptive analytic study design was carried out at juvenile delinquency in Basra Central Prison and AL- Maqal Police Station from $3^{\text {rd }}$ February 2019 until $4^{\text {th }}$ April 2019 in AL-Maqal Police Station and $14^{\text {th }}$ April 2019 until $14^{\text {th }}$ May 2019 in Basra Central Prison. Non - probability (purposive) sample of 100 juveniles who were Basra Central Prison and AL- Maqal Police Station were selected. To know the impact of mass media upon juvenile delinquency using several measures are Content-based Media Exposure Scale (C-ME), International Self-Report Delinquency Questionnaire (ISRD), and Subtypes of Antisocial Behavior questionnaire (STAB) of 60 items of statements that measure impact mass media on juvenile's behavior; and these statements are loaded into seven dimensions including social; psychological; ethical; political; economic; religious; and violent. Reliability of instrument was determined through the use of Alpha Cronbach approach and the instrument validity was determined through a panel of experts. The analysis of the data was used descriptive statistics frequencies, percentages, mean, standard deviation and Analysis of Variance (ANOVA). In order to assess the impact of mass media upon juvenile delinquency.
\end{abstract}

Results: The findings of the present study reveal that indicate to high percentage unsatisfactory behavior (44\%) in social and psychological status, (53\%) in violent status, while impact upon ethical, political, economic and religious unsatisfactory behaviors have low than third, the total percentage of unsatisfactory behavior of all sample as $(28.3 \%)$.

Conclusion: The study concluded that the unsatisfactory behavior level of (social, psychological, ethical, political, economic, religious, and violent) dimensions were moderate of juvenile delinquency.

Keyword: Impact; Mass Media; Juvenile Delinquency; Prison; Police Station.

\section{Introduction}

Mass media is a means of communication that have major role to widespread, communicate information and ideas and influence large number of people in a short duration. Therefore, advances in technology and technical capacity make mass media reach to most remote parts of the world ${ }^{14}$. Every media messages are composed of many elements like information, facts, images, sounds, beliefs, attitude, and events, individuals acquire information and store it in their memory. During media exposures, the media messages can activate some elements that already exists in the individual that are applicable through used the skills of creating something in individuals or recall of previously learned elements or incorporate these elements with others; this new information is likely to trigger negative attitudes or changes in behavior, when occur repeated exposures of the media gradually and continually making these elements more fixed and harder to change that become as individuals' behavioral patterns. This attitudes or effects might can show up immediately (during an exposure or immediately after the exposure to the media message), or it can take a long time to show up, or it can last a long 
time, or it can be temporary and disappear after a few seconds ${ }^{11}$. All people live in a society that depends on communication and information to do daily activities in the right direction, media can be present stories or issues in dramatic ways through flow of the undesirable things that covered politics issues, stories of legends, crimes and detective cases. That are unrestricted of audience and contain on amount of vulgarity, nudity and brutality with perfect blend of drama, comedy thrill, horror, emotions, action, songs or dance and romance to earning a place in juvenile's heart and mind and obscured flow good things like love, altruism, happiness, and valuable information 12. Many juveniles have problems and are getting into trouble, deal with pressures among friends and family, poverty, violence, parental problems, and gangs, truancy, a fight in school, drug or alcohol ingestion, gender, values, or ethnical, difficulty dealing with past traumas like abuse. Juvenile's independence, sometimes all these conflicts result in behavior problems, many this factors put juveniles and families at risk for juvenile delinquency and media violence can interact negatively with a juvenile's developing path of delinquency, the juvenile will apply the learned behavior at school, community, environment and attempts to force his will or assert his pride ${ }^{5}$. Juvenile delinquency is present in several countries around the world, juvenile offending increases during puberty, peaks in middle adolescence that engage or tendency in antisocial, aggressive behavior ${ }^{1}$. It is conduct that is beyond control and subject to legal action by the juvenile that is be out of line with the norms and values of society due to the misleading information from the media are full of scenes of hatred, violence, aggression and extremism that exposing to juveniles with over engaged in it used. It has a negative impact on individual, family, and society, that involve on various types of behaviors with it has multiple motivations, stimuli and consequences. In very simple words, this phenomenon leads to growing and cultivates to tendency of delinquency which threatens the peace of the society to pursue individual interests. The delinquency considers as one of the most contemporary social problems, not only in developing countries as Iraq but also in developed countries ${ }^{3}$. Juveniles commit acts of crime response to a specific motivation according personal propensities and environmental inducements, the media content have a lot of temptations through stimulate or give simple or complex ideas, and the individuals develop, and complete these ideas with make these ideas as a part of life. Therefore, media may be make unacceptable behavior of individuals make acceptable or desirable by cover negative behavior that the juveniles have responds and interaction to easily that lead to conduct or wrongful act that does not acceptable or incompatible to the moral or legal standards of community like obscenity, pilfering, loitering, gambling, drug abuse, begging ${ }^{2}$, robbery, breach of trust, cheating, extortion, possession of dangerous drugs, murder, burglary, fraud ${ }^{8}$, due to juveniles are not yet mature to distinguish or desire to selection the wrong or right of ability to self-control with engage or imitation of content the mass media ${ }^{15}$.

\section{Materials and Method}

A descriptive analytic study design was carried out at juvenile delinquency in Basra Central Prison and AL- Maqal Police Station from $3^{\text {rd }}$ February 2019 until $4^{\text {th }}$ April 2019 in AL-Maqal Police Station and 14 ${ }^{\text {th }}$ April 2019 until 14 $^{\text {th }}$ May 2019 in Basra Central Prison. Non - probability (purposive) sample of 100 juveniles who were Basra Central Prison and ALMaqal Police Station were selected. These prisoners were selected according to the following criteria: both sexes of prisoners (males and females); delinquent who were temporarily detained in police station convicted of crime, felony, or misdemeanor who is awaiting trial; and delinquent convicted of felonies or crime for punishment or rehabilitation convicted of misdemeanors and major offenses in central prison; juveniles who were at 14-17 years. For the purpose of the present study a questionnaire was designed and developed by the researcher which consists of four parts: The first part of the questionnaire concerned with determination of the sociodemographic characteristics of the sample, and the second part was habits and patterns of mass media; the third part was offenses committed by the juvenile; while last part was effect mass media on juvenile. Reliability of instrument was determined through the use of Alpha Cronbach approach $(\mathrm{r}=0.943)$, and the instrument validity was determined through a panel of (19) experts. In order to achieve the early stated objectives, the data of the study were analyzed through the use of Statistical Package of social sciences (SPSS) version 24 through statistical procedures that includes: frequency, percentage, Mean of score, standard deviation, and Analysis of Variance (ANOVA). 


\section{Results}

Table (1) Distribution of the samples by their sociodemographic characteristics of delinquent

\begin{tabular}{|c|c|c|c|c|}
\hline No. & \multicolumn{2}{|l|}{$\begin{array}{l}\text { Variables } \\
\mathrm{N}=100\end{array}$} & Frequency & $\begin{array}{l}\text { Percentage } \\
\%\end{array}$ \\
\hline \multirow{3}{*}{1} & \multirow{3}{*}{ Age } & $14-15$ & 41 & $41 \%$ \\
\hline & & $16-17$ & 59 & $59 \%$ \\
\hline & & Total & 100 & $100 \%$ \\
\hline \multirow{3}{*}{2} & \multirow{3}{*}{ Gender } & Male & 82 & $82 \%$ \\
\hline & & Female & 18 & $18 \%$ \\
\hline & & Total & 100 & $100 \%$ \\
\hline \multirow{3}{*}{3} & \multirow{3}{*}{ Residence } & Rural & 23 & $23 \%$ \\
\hline & & Urban & 77 & $77 \%$ \\
\hline & & Total & 100 & $100 \%$ \\
\hline \multirow{3}{*}{4} & \multirow{3}{*}{ Residence Area } & Slum Houses & 51 & $51 \%$ \\
\hline & & Legal Houses & 49 & $49 \%$ \\
\hline & & Total & 100 & $100 \%$ \\
\hline \multirow{4}{*}{5} & \multirow{4}{*}{ School Status } & Continuous & 15 & $15 \%$ \\
\hline & & Interrupted & 64 & $64 \%$ \\
\hline & & Did not Enter at School & 21 & $21 \%$ \\
\hline & & Total & 100 & $100 \%$ \\
\hline \multirow{4}{*}{6} & \multirow{4}{*}{ Socio-Economic Status } & High & 4 & $4 \%$ \\
\hline & & Middle & 75 & $75 \%$ \\
\hline & & Low & 21 & $21 \%$ \\
\hline & & Total & 100 & $100 \%$ \\
\hline
\end{tabular}

\section{$\mathrm{F}=$ Frequency, $\%=$ Percentage}

Table (1) The results revealed that the majority of the samples (59\%) at age 16-17 year; were male (82\%); were living in urban area $(77 \%)$ in slum houses $(51 \%)$ have interrupted at school (64\%); and middle socioeconomic status $(75 \%)$

Table (2) Distribution of the Study Sample by their Habits and Patterns of Mass Media

\begin{tabular}{|l|l|l|l|}
\hline No. & Habits and Patterns of Mass Media & Frequency & Percentage \\
\hline 1 & Read Books, Magazines Newspapers & 4 & $4 \%$ \\
\hline 2 & Watch Television & 98 & $98 \%$ \\
\hline 3 & Listen Radio & 21 & $21 \%$ \\
\hline 4 & Use the Mobile & 95 & $95 \%$ \\
\hline 5 & Use the Internet & 86 & $86 \%$ \\
\hline 6 & Use the Personal Computer & 6 & $6 \%$ \\
\hline 7 & Watch the Cinema and Theater & 0 & $0 \%$ \\
\hline
\end{tabular}




\section{F $=$ Frequency,$\quad \%=$ Percentage}

Table (2) The results revealed that the samples of habits and patterns of mass media were (98\%) watch television; (95\%) use the mobile; (86\%) use the internet; $(21 \%)$ listen radio; $(6 \%)$ use the personal computer, while $(0 \%)$ were watch the cinema and theater.

Table (3) Distribution of the Study Sample the Offenses and Misdemeanor Committed by the Juveniles

\begin{tabular}{|l|l|l|l|}
\hline No. & $\begin{array}{l}\text { Types of Offenses and Misdemeanor Committed by the } \\
\text { Juveniles }\end{array}$ & Frequency & Percentage \\
\hline 1 & Theft & 29 & $29 \%$ \\
\hline 2 & Rape & 13 & $13 \%$ \\
\hline 3 & Drug Abuse & 21 & $21 \%$ \\
\hline 4 & Murder & 17 & $17 \%$ \\
\hline 5 & Beatings & 4 & $4 \%$ \\
\hline 6 & Kidnapping & 2 & $2 \%$ \\
\hline 7 & Threat & 1 & $1 \%$ \\
\hline 8 & Vagrancy & 5 & $5 \%$ \\
\hline 9 & Motorcycle/ Car Accidents & 0 & $0 \%$ \\
\hline 10 & Forgery & 5 & $5 \%$ \\
\hline 11 & Cheating & 0 & $0 \%$ \\
\hline 12 & Betrayal & 2 & $2 \%$ \\
\hline 13 & Sabotage & 1 & $1 \%$ \\
\hline 14 & Total & 100 & $100 \%$ \\
\hline
\end{tabular}

\section{F= Frequency,$\quad \%=$ Percentage}

Table (3) The results revealed that the samples of types of offenses and misdemeanor committed by the Juveniles that indicate to $(29 \%)$ theft; $(21 \%)$ drug abuse; (17\%) murder; (13\%) rape; $(5 \%)$ were vagrancy and forgery; while were $(0 \%)$ motorcycle/ car accidents and cheating.

Table (4) Assessment Juvenile's Behavior Levels and Test the Impact of Mass Media upon Juveniles among Study Group.

\begin{tabular}{|l|l|l|l|l|l|}
\hline \multirow{2}{*}{ No. } & \multirow{2}{*}{ Item } & \multicolumn{2}{|l|}{ Juvenile's Behavior Levels } & \multirow{2}{*}{ Total } \\
\cline { 3 - 5 } & & Unsatisfactory & Moderate & Good & \\
\hline 1 & Social and Psychological & $43 \%$ & $40 \%$ & $17 \%$ & $100 \%$ \\
\hline 2 & Ethical Status & $23 \%$ & $34 \%$ & $43 \%$ & $100 \%$ \\
\hline 3 & Political & $8 \%$ & $18 \%$ & $74 \%$ & $100 \%$ \\
\hline 4 & Economic Status & $32 \%$ & $29 \%$ & $39 \%$ & $100 \%$ \\
\hline 5 & Religious Status & $18 \%$ & $35 \%$ & $47 \%$ & $100 \%$ \\
\hline 6 & Violent Effect & $53 \%$ & $34 \%$ & $13 \%$ & $100 \%$ \\
\hline 7 & General Negative Effects & $21 \%$ & $53 \%$ & $26 \%$ & $100 \%$ \\
\hline 8 & Total Juvenile's Behavior & $28.3 \%$ & $34.7 \%$ & $37 \%$ & $100 \%$ \\
\hline
\end{tabular}




\section{$\mathrm{F}=$ Frequency,$\quad \%=$ Percentage}

Table (4) The results revealed that the samples of juvenile's behavior levels that indicate to high percentage unsatisfactory behavior $(43 \%)$ were social and psychological status; (53\%) were violent status; while $(28.3 \%)$ were total juvenile's behavior as unsatisfactory behavior.

\section{Discussion}

The results revealed that the majority of the samples (59\%) at age $16-17$ year, while $14-15$ year were $(41 \%)$; more than three-quarters $(82 \%)$ the samples were male and the rest of the sample were females; more than three-quarters $(77 \%)$ were living in urban area, while were little more than half (51\%) living in slum houses; the majority of the samples have interrupted at school $(64 \%)$ and third (21\%) the juveniles were did not enter at school; with three-quarters (75\%) of juvenile's families have middle socioeconomic status, while $(21 \%)$ were juvenile's families have low socioeconomic status. Concerning the results of the habits and patterns of mass media before enter the prison, the juveniles were (98\%) watch television; (95\%) use the mobile; (86\%) use the internet, this finding agrees and supported with results obtained from study done by (Mangwere et al, 2013) it indicates to more use the juveniles of mass media are watch television $(100 \%)$, use the mobile $(72 \%)$ and use the internet (56\%); while listen radio were $(21 \%)$; $(6 \%)$ were used the personal computer, while $(0 \%)$ were watch the cinema and theater of study sample.

Regarding the types of offenses and misdemeanor committed by the Juveniles that indicate to $(29 \%)$ theft; (21\%) drug abuse; (17\%) murder; (13\%) rape; $(5 \%)$ were vagrancy and forgery; while were $(0 \%)$ motorcycle/ car accidents and cheating. this finding agrees and support with results obtained from study done by (Hameed, 2011); reports indicate theft (38.13\%), drug abuse $(17.79 \%)$, also this finding agree with results obtained from study (Chowdhury et al, 2012) that indicate to theft (47.37\%) and murder (36.84\%)and other commit a misdemeanor. This result due to the juveniles attract to delinquent behavior due to inspired by media.

Concerning the juvenile's behavior levels that indicate to high percentage unsatisfactory behavior (43\%) were social and psychological status; (53\%) were violent status; while (28.3\%) were total juvenile's behavior as unsatisfactory behavior. This finding agree with results obtained from studies (Helles and Mahdi, 2010); (Saleem et al, 2013) and (Hammond and Ioannou, 2015) all these studies indicate to high unsatisfactory behavior in social and psychological and violent status of delinquency juveniles.

\section{Conclusions}

The findings of the present study conclude that the mass media have impact upon juveniles that lead to unsatisfactory juvenile's behavior in social, psychological status with occur violent effect that lead the juveniles to broken the law and then delinquency.

Financial Disclosure: There is no financial disclosure.

Conflict of Interest: None to declare.

Ethical Clearance: All experimental protocols were approved under the Ministry of Health and all experiments were carried out in accordance with approved guidelines.

\section{References}

1. Abdullah H, Ortega A, Ahmad N. and Ghazali S. Aggressive and Delinquent Behavior among High Risk Youth in Malaysia, Asian Social Science. 2012; 11(16): 62-68.

2. Ahsan T. Words of Juvenile Delinquency Unveiling the Truth, Department of Criminology, University of Dhaka. 2017; 2.

3. Chingtham T. Causes of Juvenile Delinquency in the Higher Secondary School Students, Journal of Research and Method in Education (IOSR-JRME). 2015; 5(5): 20-24.

4. Chowdhury I, Khan M, Uddin I. Causes and Consequences of Juvenile Delinquency in Bangladesh: A Sociological Analysis, International Journal of Social Science Tomorrow. 2012; 1(4): 2-10.

5. Falodun O K. Role of The Mass Media in Relation to Crime and Deviance, University College Cork, Ireland. 2012 Jan; 1-29.

6. Hameed F. Personality of the Juvenile delinquency, University of Abou Bekr Belkaid, Faculty of Humanities and Social Sciences, Department of 
Popular Culture, Algeria. 2011; 125-140.

7. Hammond L, Ioannou M. Age Effects on Juvenile Homicide Perpetration, International Research Centre for Investigative Psychology, University of Huddersfield. 2015; 4-25.

8. Helfgott J B. Criminal behavior and the copycat effect: Literature review and theoretical framework for empirical investigation. Aggression and Violent Behavior. 2015;22(C):46-64.

9. Helles M A. and Mahdi N A. The Role of Media in Shaping Social Awareness Among Palestinian Youth, Journal of Al-Azhar University in Gaza, Humanities Series. 2010; 2(12): 163-169.

10. Mangwere A, Wadesango $\mathrm{N}$, Kurebwa $\mathrm{M}$. Influence of the Electronic Media on the Behavior of Children/ Teenagers in Zimbabwe, Kamla-Raj Communication. 2013; 4(2): 101-109.
11. Potter W J. Media Effects, Chapter three, What Is a Media Effect, SAGE Publishing, University of California, Santa Barbara. 2012; 35-48.

12. Ranjana M, Kulkarni R, Sherke V A. Dhond P P. and Pardeshi T P. Recent Genre Based Categorized Comparisons of Bollywood Movies Through Radar Plots, International Journal of Innovative Technology and Research. 2016; 4(2): 2844 - 2845.

13. Saleem N. Ahmed S. Hanan M. A.and Haroon S. Violent Movies and Criminal Behavior of Delinquents, Pakistan Journal of Social Sciences (PJSS). 2013; 33(2): 243-254.

14. Soleymani M R, Garivani A, Farashbandi F Z. The Effect of the Internet Addiction on the InformationSeeking Behavior of the Postgraduate Students, Mater Sociomed. 2016; 28(3): 191-195.

15. Wikström $\mathrm{O} H$. Why crime happens: A situational action theory, Gianluca Manzo, First Edition. 2013;75-90. 